\title{
Regenerative Potential of Direct Adipose Tissue Stimulation: A Pilot Study on Skin Improvement
}

\author{
Alberto Diaspro* \\ Maxillo-facial Surgeon, Master of Science in Aesthetic Medicine, Italy
}

*Corresponding author: Dr Alberto Diaspro, Rigeneralab Centre for Regenerative Medicine Corso Unione Sovietica 159/a, 10134, Turin, Italy

\section{ARTICLE INFO}

Received: 㓞 April 13, 2019

Published: April 24, 2019

Citation: Alberto Diaspro. Regenerative Potential of Direct Adipose Tissue Stimulation: A Pilot Study on Skin Improvement. Biomed J Sci \& Tech Res 17(3)-2019. BJSTR. MS.ID.002990.

Abbreviations: ASCs: Adipose-derived Stem Cells; VEGF: Vascular Endothelial Growth Factor; IGF: Insulin-Like Growth Factor; HGF: Hepatocyte Growth Factors; TGF- $\beta$ : Transforming Growth Factor; BAT: Brown Adipose Tissue; PEFS: Panniculopatia-Edemato-Fibro-Sclerotic; NEFA: Non-Esterified Fatty Acids; PDC: Phosphatidylcholine Solution; DC: Desoxycholate; PDGF: Platelet-Derived Growth Factor; BFGF: Basic Fibroblast Growth Factor; POB: Periombelical; PTR: Peritrocanteric

\section{ABSTRACT}

Introduction: Subcutaneous adipose tissue presents with a regenerative potential that may correct aesthetically unpleasant flaws due to skin aging. Intra-adipose injection techniques have also been described in the literature and their aim is to allow body remodeling together with an aesthetic improvement. The outpatient technique here presented, has characteristics from both aforementioned treatment techniques.

Methods: the aim of this work is to assess regenerative potential of direct adipose tissue stimulation by its effects on skin texture and dermal thickness after the intra-adipose action of a sharp needle and injection of a dilute solution of phospholipids. No anesthesia, even local, was performed. The evaluation on a series of patients treated was carried out clinically, by means of photography and GAIS (Global Aesthetic Improvement Scale), and instrumentally by ultra-sound examination and histological sample.

Results: the technique has shown to enhance skin texture and thickenss, as highlighted in the presented series and in the histological sample.

Conclusions: growth factors produced by Adipose-derived Stem Cells (ASCs) can therefore affect aesthetic improvements and provide stimuli for cellular renewal processes. A larger series will allow to validate the presented findings.

\section{Introduction}

Subcutaneous adipose tissue plays a key role in the aging process of the skin: its vasculo-stromal component is in fact a reserve of cells with regenerative potential, able to release factors that stimulate cell differentiation in order to correct aesthetic flaws [1]. The use of adipose tissue according to Coleman's technique [2,3], implanted in order to achieve filling and regenerative purposes in scarry or healthy tissue, represents a mainstay method in aesthetic medicine and surgery. The mesenchymal cells found in adipose tissue, so called Adipose-derived Stem Cells (ASCs), were identified in 2001 and since then this tissue has been considered for its role in regenerative medicine [4]. The isolated ASCs have different characteristics but their anatomical localization is always in the perivascular stroma, between the endothelium and the adipocyte. They produce many growth factors: basic fibroblast growth factor
(bFGF in the damaged cellular matrix), vascular endothelial growth factor (VEGF which increases migration and promotes chondrogenic differentiation), insulin-like growth factor (IGF), hepatocyte growth factors (HGF, which promotes hepatogenetic differentiation), transforming growth factor (TGF- $\beta$ ), and they react to the proliferative action of $\mathrm{bFGF}$ and platelet-derived growth factor (PDGF, secreted by platelets in endothelial damage site), and express different receptors for growth factors, thus mediating tissue differentiation.

They differentiate into cells of ectodermal, endodermal and mesodermal origin [5].

Adipose tissue is similar to an endocrine organ and plays a pivotal role in controlling the body's energy balance. Two adipose tissue types have been identified: the brown one (BAT, Brown 
Adipose Tissue), which has a metabolic role in energy production, hence dissipated as heat for the endogenous thermoregulation, and the white one (WAT, White Adipose Tissue), used as a storage function for energy deposit such as triglycerides. Of the latter, on the basis of structural and extra-structural characteristics, three types of light adipose tissue (WAT) can be identified: the storage/ deposit (dWAT), the structural (sWAT) and the fibrous (fWAT) tissue. Beige adipocytes have intermediate characteristics: they are cells located in light adipose tissue in the inguinal region, with the role of adaptive thermogenesis [6,7].

The lipolytic treatments, to be preferred in the subject of young age and with initial stages of panniculopatia-edematofibro-sclerotic (PEFS), do not cause damage to adipose tissue and therefore do not trigger reparative processes that result in increased intra-adipocyte fibrosis.

In elder patients, even with more significant adipose excess, lipoclasic treatments are indicated, which however result in an increase in fibrosis with evident results on the skin texture which, although clinically improved, suffers from structural damage. In the medical treatment of adipose excesses associated with PEFS it is therefore necessary to take into account the role of the fibrous component which, by seizurung adipocytes, accounts for the partial failures of the available therapeutic options. Various techniques of intra-adipose administration of therapeutic substances are available in the literature in order to obtain an improvement in the body profile. The triglycerides emulsification after chemical cell lysis, and their subsequent reabsorption as non-esterified fatty acids (NEFA), has been reported since 2004, when it was placed at the base of the efficacy of the lipoclasic treatment with phosphatidylcoline (PDC) and desoxycholate (DC) solution whose effects on organic tissues have been known before they were evaluated with respect of this topic and clarified the applications in the medical aesthetic field, as an agent responsible for the rupture of adipocyte membranes with consequent cellular necrosis and morphological alteration of the adipose tissue of the treated site [8-10].

Methods of fat emulsification with profiles of lesser morbidity and equal efficacy have subsequently been proposed since the histology of this reaction has been described on tissues in vivo (lipomas) and on living volunteers such as a neutrophilic lobular panniculitis, induced by injection or implantation of foreign substances, with early secretion of pro-inflammatory cytokines such as IL-4, IL-6, IL-8, IL-10 and TNF-alpha, presence of inflammatory infiltrate composed mainly of neutrophils in the early lesions that changes towards a granulomatous process in the late lesions, with surrounding fibrosis [11-14]. The intra-adipose administration of PDC-DC also results in a dose and time dependent decrease in fibroblastic vitality, with effects similar to those of other laboratory detergents, and histological studies have shown that PDC and DC have toxic effects also on other tissues, with necrosis of muscle tissue and apoptosis at doses less than $50 \%$ in 48 hours compared to that required to induce adipocyte apoptosis. The same can be said about endothelial cell lines [15].

Subcutaneous injection of sole PDC solution therefore appears to be relatively effective in reducing subcutaneous adipose tissue, although membrane damage is not limited to adipocytes alone $[16,17]$. Preliminary experiments on PDC formulation have in fact demonstrated the lysis of keratinocyte membranes in vitro [17]. PDC-DC injection induces necrosis of adipose tissue and adipocyte apoptosis within 48 hours $[18,19]$, but cultured cells exposed to significant concentrations of DC, an endogenous biliary detergent that emulsifies fats introduced into the gastrointestinal tract, they die quickly due to membrane rupture, and this effect is not specific for cell type. DC injection is clinically tolerated and induces reduction of fat tissue and non-destruction of muscle and skin due to a mechanism of steric limitation of its action at the injection site in fat tissue: the physiological concentration of albumin in proteinrich tissues (such as muscle and skin) inactivate DC-mediated cell lysis. However, since adipose tissue has the most low-protein human tissue content, it is highly sensitive to DC damage. Thus the DC injected into the fat is rapidly neutralized by albumin or by the insoluble proteins associated with the tissue.

Once complexed with plasma albumin, DC enters the systemic circulation and it is directed to the liver, where fatty acid carriers remove it from the circulation and add it to the endogenous pool of bile acids: it is therefore the action of albumin to make the DC injected biocompatible. The treatment of adipose cells in culture with DC is therefore dose-dependent cytotoxic: human fibroblasts and muscle cells are less susceptible to it, whereas human keratinocytes are more susceptible [20,21]. Hypothalamic phospholipids have shown efficacy in micellizing fatty acids with significantly higher safety profiles [11] even if they unfortunately show any lipolytic activity. Local stimulation of adipose tissue has characteristics common to both treatment, in the cellular component it favors endogenous lipolysis after micellization of the triglycerides by the injected hypothalamic phospholipids, and the surgical section of the fibrous one triggers reparative processes, slightly affecting the threedimensional volume of localized adiposity.

As already reported in the literature, tissue effects are found in the subcutaneous fat also by injecting isolated physiological solution [7], favoring the appearance of reparative processes in the tissue in which the aesthetic improvements could be the visible result.The ASCs have a fibroblastic morphology, with well represented endoplasmic reticulum and nucleus. Cutaneous wounds treated with ASCs showed faster healing with epithelial migration and angiogenesis, with better tissue quality and less scar tissue formation, characteristics confirmed by studies on human keratinocytes in vivo [22]. The ASCs are isolated from the vascular stroma directly in the lipo-aspirate, therefore easily accessible to the surgeon for harvesting and subsequent grafting [23], even when the adipose tissue is not stimulated directly as in this case. Lipoaspirate contains VEGF and other growth factors: basic fibroblast growth factor (bFGF), insulin-like growth factor (IGF) and platelet-derived growth factor (PDGF), necessary for engraftment of grafted tissue and secreted by ASCs [24] but which could also act locally as an adequate regenerative stimulus. The purpose of this study is to evaluate the skin texture improvement after local stimulation of adipose tissue on a small patient population. 


\section{Materials and Methods}

Between January and October 2014, 7 patients were treated, 6 females and 1 male, aged between 25 and 52 years (average age 37.7 years). The study protocol provided for four monthly sessions, photographic evaluation and ultrasound examination on first and last session. All the patients were informed and signed written consent.

The presence of both acute or chronic phase metabolic or cutaneous pathologies have been considered exclusion criteria from the study along with pharmacological therapies. All patients presented with INR values and platelet counts in physiological ranges. The sites treated were the periombelical (POB), peritrocanteric (PTR) zone, and the flanks (F). Ultrasound measurements of the thickness of the subcutaneous adipose panniculus are the single periombelical measurement and the average of the three measurements, at the cranial pole, middle and caudal, of the peritrochanteric site, expressed in millimeters

GAIS (Global Aesthetic Improvement Scale) scales were used for subjective evaluation of the texture (Gais Tex) and of the skin consistency of the treated site (Gais Cons), with numerical evaluation criterion: worsened 0 , normal 1 , improved 2 , much improved 3. The data of the study population are summarized in (Table 1).

Table 1: Study Results: Adipose tissue thickness variations on ultrasounds (expressed in mm), Gais score.

\begin{tabular}{|c|c|c|c|c|c|c|c|c|c|c|c|c|c|}
\hline$\#$ & name & age & site & $\begin{array}{l}\text { t0 } \\
\mathrm{dx}\end{array}$ & $\begin{array}{l}\mathrm{t} 1 \\
\mathrm{dx}\end{array}$ & $\begin{array}{l}\text { delta } \\
\mathrm{dx}\end{array}$ & $\begin{array}{l}\text { t0 } \\
\mathrm{sx}\end{array}$ & $\begin{array}{l}\mathrm{t} 1 \\
\mathrm{sx}\end{array}$ & $\begin{array}{c}\text { delta } \\
\text { sx }\end{array}$ & strie & $\begin{array}{l}\text { Gais } \\
\text { Tex }\end{array}$ & $\begin{array}{l}\text { Gais } \\
\text { Cons }\end{array}$ & tot \\
\hline 1 & A.D. & 37 & РОВ & 2,58 & 1,73 & $-0,85$ & 2,93 & 2,05 & $-0,88$ & 0 & 1 & 1 & 2 \\
\hline 2 & AL.D. & 35 & PTR & 4,1 & 3,98 & $-0,12$ & 4,32 & 4,28 & $-0,04$ & 0 & 1 & 2 & 3 \\
\hline 3 & F.G. & 32 & $\mathrm{~F}$ & 1,49 & lost & & 1,8 & lost & & & & & \\
\hline 4 & R.F. & 45 & РОВ & 2,25 & 2,5 & $-0,25$ & 1,91 & 1,81 & $-0,1$ & 0 & 3 & 2 & 5 \\
\hline 5 & C.G. & 25 & PTR & 3,3 & 3,72 & $-0,42$ & 4,4 & 3,22 & $-1,18$ & 1 & 1 & 1 & 2 \\
\hline 6 & V.S. & 52 & PTR & 4,3 & 4,08 & $-0,22$ & 4,3 & 3,83 & $-0,47$ & 0 & 1 & 2 & 3 \\
\hline 7 & K.I. & 38 & РОВ & 1,95 & 1,86 & $-0,09$ & 1,78 & 1,9 & 0,12 & 0 & 2 & 2 & 4 \\
\hline
\end{tabular}

The treatment protocol included injection, using 22G intralipotherapy needles of length $90 \mathrm{~mm}$, of $5 \mathrm{ml}$ per side of solution consisting of $4.8 \mathrm{ml}$ of saline $\mathrm{NaCl} 0.9 \%$ and $0.2 \mathrm{ml}(2.8 \mathrm{mg})$ of hypothalamic phospholipids (Liposom Forte vials $28 \mathrm{mg} / 2 \mathrm{ml} \mathrm{0,2}$ ml - Via Ponte della Fabbrica 3/A - 35031 Abano Terme PD - Italy). The solution is injected into the subcutaneous adipose tissue with a fan technique and retrograde injection. The inoculation plan is subcutaneous with painless tunneling. Once entered in the subcutaneous fat the needle is moved, while injecting the solution, forward and back in order to cut the fibrous septa of the adipose tissue. The ultrasound study was performed using a Mindray Bio-Medical Electronics Co., Ltd. - Shenzhen (China) probe with ultrasound at $10 \mathrm{Mhz}$, in order to evaluate: the thickness of the subcutaneous adipose tissue in the treated site the presence of fibrotic striae in the panniculus ( 0 if unchanged, 1 if increased) at t 0 and for the subsequent post-treatment revaluation $\mathrm{t} 1$. Pre and post-treatment clinical photos were taken using an 8-megapixel iSight autofocus camera. For histological confirmation of clinical and instrumental findings, a split-belly study has been conducted on a patient candidate for and abdominoplasty left-right case-control treatment with saline and study solution was performed in the previous 4 months, then the cutaneous sample removed by the surgeon in order to perform microscopic study of the skin layers thickness.

\section{Results}

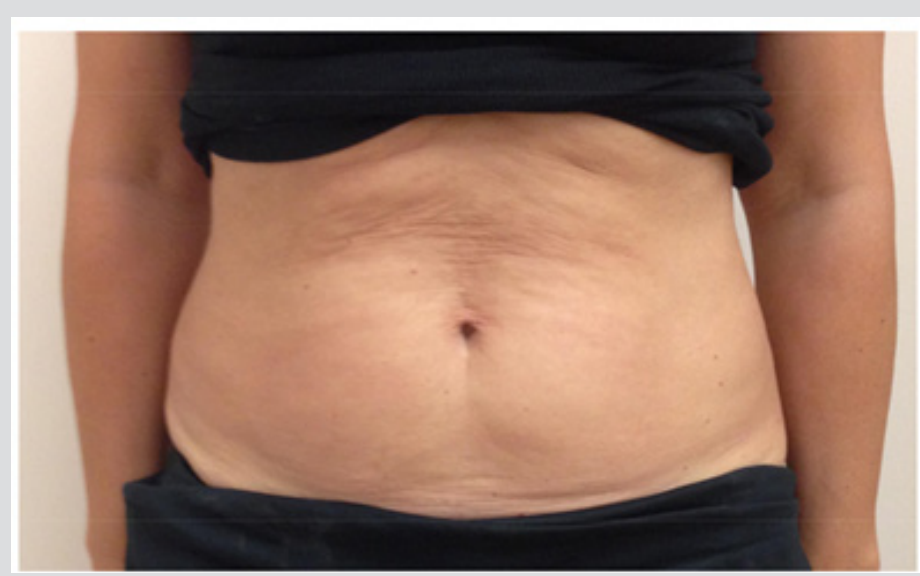

Figure 1: Pz 4 Pre-treatment. 


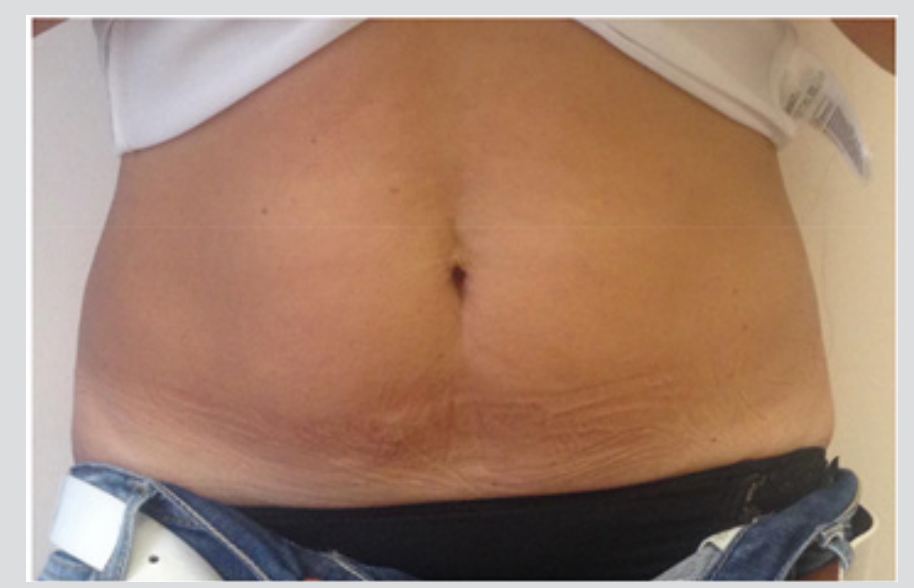

Figure 2: Pz. 4 Post-treatment.

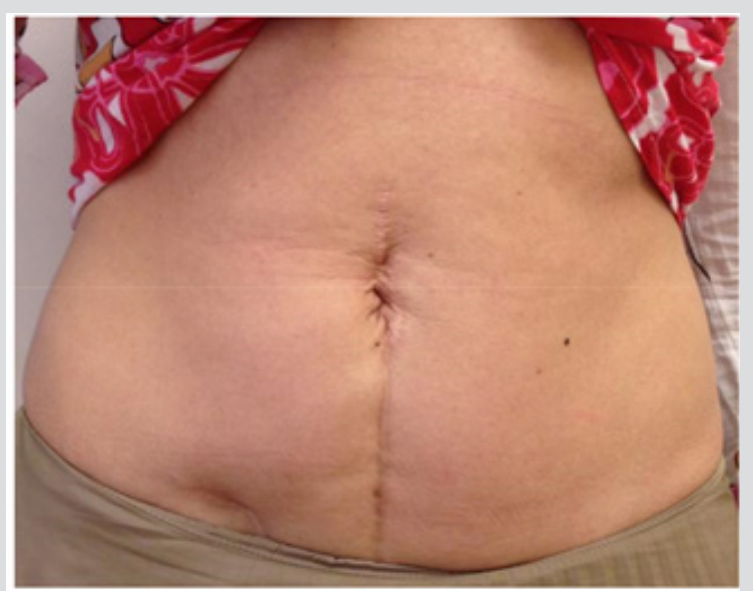

Figure 3: Pz. 7 Pre-treatment.

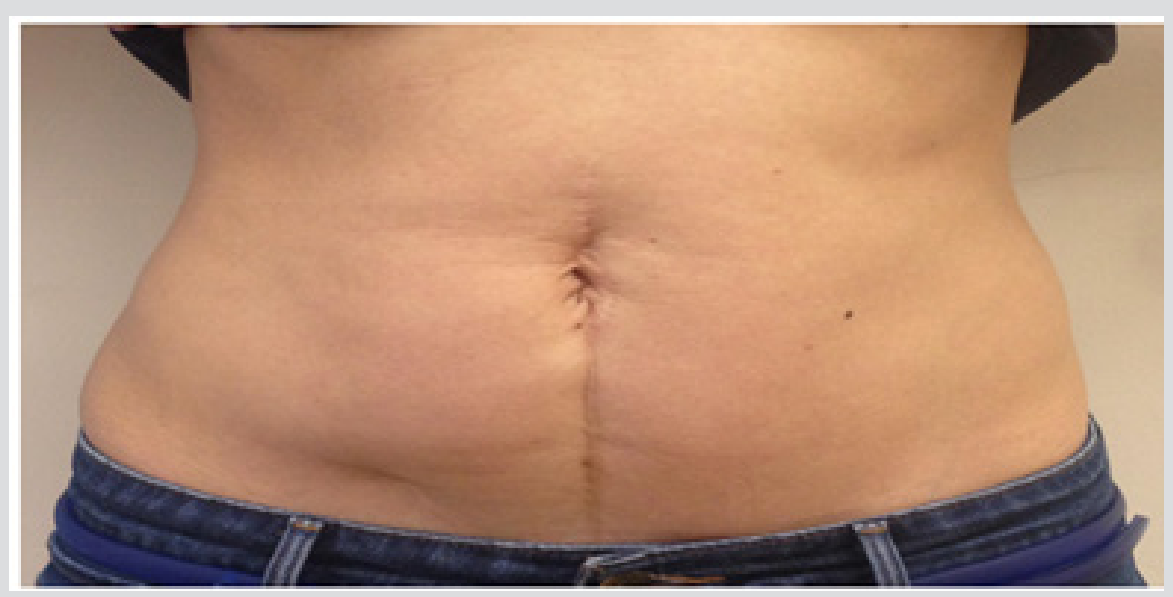

Figure 4: Pz.7 Post-treatment.

No significant changes in the thickness of the subcutaneous adipose tissue was observed, and was not possible to correlate it with a direct clinical effect of the performed sessions. In only one case the increase in the fibrosity of the treated panniculus was observed: it is a patient with athletic habit and poor panniculus and her treatment sessions were painful, due to the paucity of adipose tissue and a well-represented fibrous component. In no other case fat fibrosis has shown to be increased. The improvement of the skin texture appeared to be relevant from the clinical photos and from the analysis of the GAIS scales in skin in the periombelical area (Figures 1-4). The skin thickness increase in both of the treated skin samples is considered to be evident on histological evaluation, stained with hematoxylin-eosin on material fixed in formalin (Figure 5A,B \& $6 \mathrm{~A}, \mathrm{~B})$. No organized hematomas or other nodular formations 
were found in the treated sites, and on ultrasound examination the adipose tissue appeared in physiological conditions. Common occurrence has been the appearance of erythema and papules at injection sites, with spontaneous resolution in the hours following the treatment. Ecchymoses can be seen from the following images (Figure 7). No other adverse events were detected.

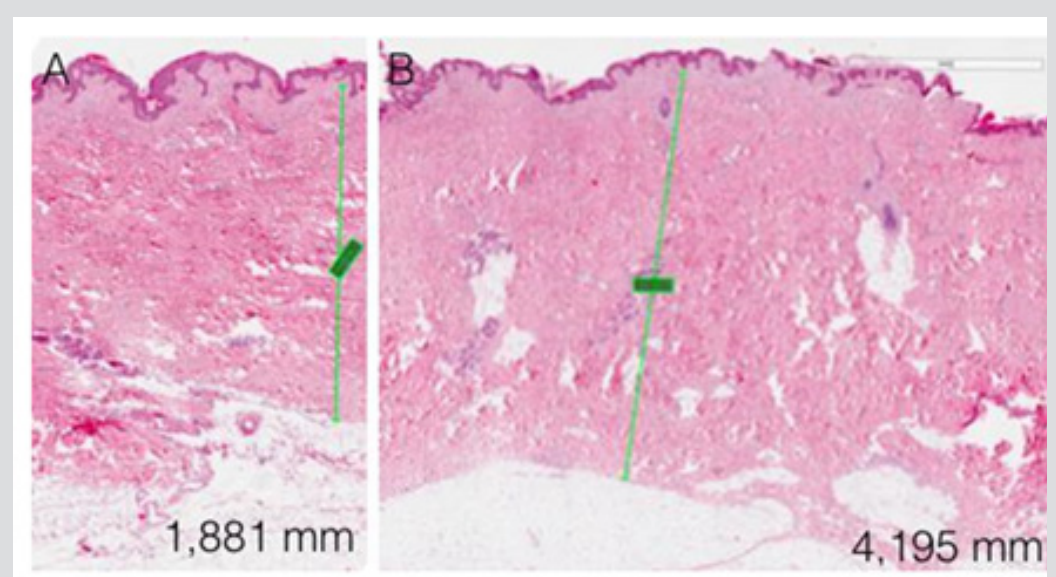

Figure 5: Dermal Thickness: untreated sample (A) and treated sample (B).

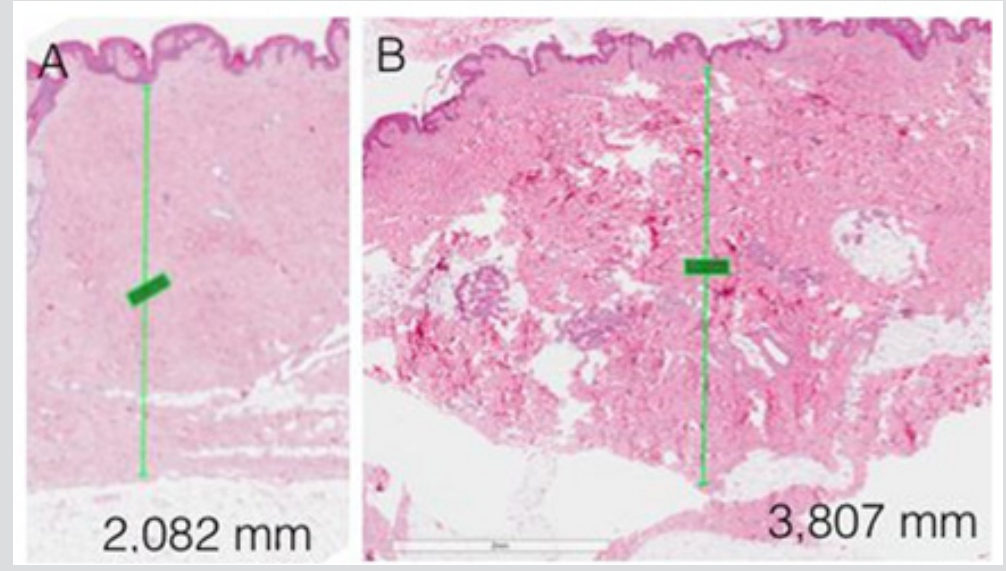

Figure 6: Dermal Thickness: untreated sample (A) and treated sample (B).

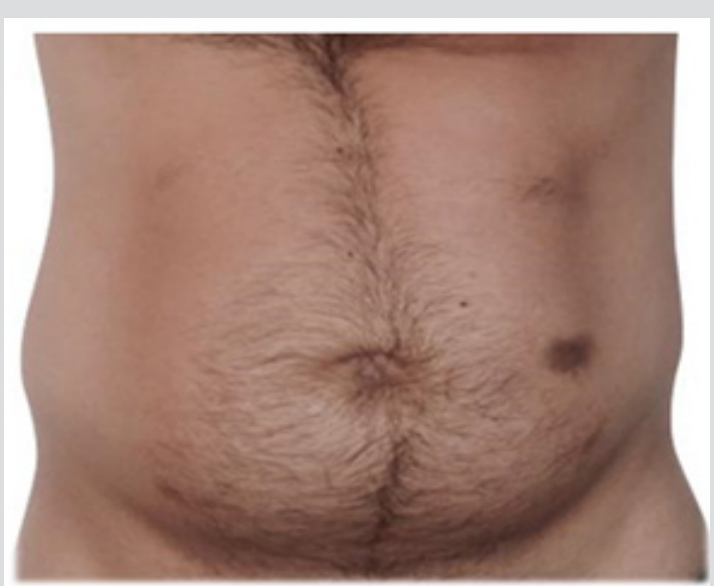

Figure 7: Post- treatment ecchimosis. 


\section{Discussion}

The needle determines the surgical section of the fat cells, lobular septa and peri-adipocyte stroma: the cell membrane disruption is accompanied by the micellization of the triglycerides done by injected phospholipids, with a oil-in-water emulsification. Tissue damage to the lobular septa of the peri-adipocyte stroma triggers healing processes whereas the regenerative factors of adipose tissue are actively involved.

The ASCs produce TGF-beta, VEGF, KGF, FGF2, PDGF, HGF, fibronectin and collagen, all are associated with stimulation of the healing process in normal and chronic wounds, via the paracrine route.

The growth factors produced by ASCs can therefore have aesthetic effects and produce improvement of the physiological processes of cell renewal, As confirmed by the clinical results and in histological sample. Their role has also been evaluated in delaying the appearance of photo-induced wrinkles both in vivo and in vitro: a protective effect was observed from the UVB effects in fibroblasts grown with ASC. Studies on guinea pigs have confirmed that the subcutaneous injection of ASC delayed the appearance of wrinkles after exposure to UVB rays.

It is assumed that they can both induce tissue regeneration and differentiate into cells of the skin (fibroblasts and keratinocytes) both by secretion of factors with paracrine action, stimulating angiogenesis, epithelization and tissue remodelling [22]. The absence of any irreversible sequela on adipose tissue ascertained by ultrasound checks post-treatment allows to propose repeated therapy cycles with potentially cumulative benefits, minimizing post-treatment discomfort.

\section{Conclusion}

The adipose tissue in-situ stimulation treatment has interesting potential for tissue regeneration, with a significant improvement in texture and skin quality, as seen in the cases presented and appreciated by the patients themselves. The histology confirms the skin thickness increase observed in the treated site with respect for the untreated site. The findings appear to be secondary to the regenerative stimulus of the treated adipose tissue which are directly stimulated by the technique, and they confirm the sound evidence of skin amelioration related to adipose tissue grafting. The morbidity of the treament, when performed by an experienced practicioner, is low without major side effects, with extreme patient satisfaction. The increase of numerosity of the study population will allow to validate the preliminary data presented in this pilot study.

\section{References}

1. Cordova A, Liuzza C, Pirrello R (2010) Regenerative potential of lipofilling on skin aging. BMC Geriatrics10(1): A54.

2. Coleman SR (1995) Long-term survival of fat transplants: controlled demonstrations. Aesthetic Plast Surg. 19(5): 421-425.

3. Coleman SR (1997) Facial recontouring with lipostructure. Clin Plast Surg 24(2): 347-367.

4. Zuk PA, Zhu M, Mizuno H (2001) Multilineage cells from human adipose tissue: implications for cell-based therapies. Tissue Eng 7(2): 211-228.
5. Park A, Kim WK, Bae KH (2014) Distinction of white, beige and brown adipocytes derived from mesenchymal stem cells. World J Stem Cells 6(1): 33-42.

6. Sbarbati A, Accorsi D, Benati D (2010) Subcutaneous adipose tissue classification. Eur J Histochem 54(4): e48.

7. Tsuji W, Rubin JP, Marra KG (2014) Adipose-derived stem cells: Implications in tissue regeneration. World J Stem Cells 6(3): 312-321.

8. Salti G, Rauso R (2014) Comments on Injection lipolysis with phosphatidylcholine and deoxycholate. Aesthet Surg J 34(4): 639-640.

9. Martin GP, Marriott C, Kellaway IW (1978) Direct effect of bile salts and phospholipids on the physical properties of mucus. Gut 19(2): 103-107.

10. Rotunda AM, Suzuki H, Moy RL, Kolodney MS (2004) Detergent effects of sodium deoxycholate are a major feature of an injectable phosphatidylcholine formulation used for localized fat dissolution. Dermatol Surg 30(7): 1001-1008.

11. Motolese P (2008) Phospholipids do not have lipolytic activity. A critical review. J Cosmet Laser Ther 10(2): 114-118.

12. Bechara FG, Sand M, Hoffmann K, Sand D, Altmeyer P, et al. (2007) Fat tissue after lipolysis of lipomas: A histopathological and immunohistochemical study. J Cutan Pathol 34(7): 552-557.

13. Bechara FG, Skrygan M, Kreuter A, Altmeyer P, Gambichler T (2008) Cytokine mRNA levels in human fat tissue after injection lipolysis with phosphatidylcholine and deoxycholate. Arch Dermatol Res 300(8): 455459.

14. Schuller Petrovic S, Wölkart G, Höfler G, Neuhold N, Freisinger F, et al. (2008) Tissue-toxic effects of phosphatidylcholine/deoxycholate after subcutaneous injection for fat dissolution in rats and a human volunteer Dermatol Surg 34(4): 529-543.

15. Gupta A, Lobocki C, Singh S (2009) Actions and comparative efficacy of phosphatidylcholine formulation and isolated sodium deoxycholate for different cell types. Aesthetic Plast Surg 33(3): 346-352.

16. Klein SM, Schreml S, Nerlich M, Prantl L (2009) In vitro studies investigating the effect of subcutaneous phosphatidylcholine injections in the 3T3-L1 adipocyte model: lipolysis or lipid dissolution? Plast Reconstr Surg 124(2): 419-27.

17. Ablon G, Rotunda AM (2004) Treatment of lower eyelid fat pads using phosphatidylcholine: clinical trial and review. Dermatol Surg 30(3): 422-427.

18. Bechara FG, Mannherz HG, Jacob M (2012) Induction of fat cell necrosis in human fat tissue after treatment with phosphatidylcholine and deoxycholate. J Eur Acad Dermatol Venereol 26(2):180-185.

19. Reeds DN, Mohammed BS, Kiein S, Boswell CB, Young VL (2013) Metabolic and structural effects of phosphatidylcholine and deoxycholate injectionson subcutaneous fat: a randomized, controlled trial. Aesthetic Surgery Journal 33(3): 400-408.

20. Thuangtong R, Bentow JJ, Knopp K, Mahmood NA, David NE, et al. (2010) Tissue-selective effects of injected deoxycholate. Dermatol Surg 36(6): 899-908.

21. Rittes PG (2009) The lipodissolve technique: clinical experience. Clin Plastic Surg 36(2) :215- 221.

22. Hassan WU, Greiser U, Wang W (2014) Role of adiposederived stem cells in wound healing. Wound Repair Regen 22(3): 313-325.

23. Tabit CJ, Slack GC, Fan K, Wan DC, Bradley JP (2012) Fat grafting versus adipose-derived stem cell therapy:distinguishing indications, techniques, and outcomes. Aesthetic Plast Surg 36(3): 704-713.

24. Alharbi Z, Opländer C, Almakadi S, Fritz A, Vogt M, et al. (2013) Conventional vs. micro-fat harvesting: How fat harvesting technique affects tissue-engineering approaches using adipose tissue-derived stem/stromal cells. J Plast Reconstr Aesthet Surg 66: 1271-1278. 


\section{ISSN: 2574-1241}

DOI: 10.26717/BJSTR.2019.17.002990

Alberto Diaspro. Biomed J Sci \& Tech Res

(C) (i) This work is licensed under Creative

Submission Link: https://biomedres.us/submit-manuscript.php

$\begin{array}{ll}\text { BIOMEDICAL } & \text { Assets of Publishing with us } \\ \text { RESEARCHES } & \text { - Global archiving of articles } \\ & \text { - Immediate, unrestricted online access } \\ \end{array}$

